\title{
Legal and policy issues in rural and remote medicine
}

Saad Ahmed (Meds 2016)

Faculty Reviewer: Dr Kevin Coughlin, MD, FRCPC, MHSc (Department of Pediatrics, Division of Maternal, Fetal \& Newborn Health)

Almost 15 years ago, Health Canada's Special Advisor on Rural Health declared,

"If there is two-tiered medicine in Canada, it's not rich and poor, it's urban versus rural."

That significant health inequities exist between rural areas and urban areas should not be surprising-it is the reasons for these inequities that are complex and often full of surprises.

\section{BROAD OVERVIEW OF THE ISSUES}

While an exact definition of "rural" is contentious, according to Health Canada roughly $20.3 \%$ of Canada's population in 2001 lived in rural areas, ${ }^{2}$ and about $95 \%$ of Canada's land mass is considered rural. ${ }^{3}$ There exists a vast diversity amongst rural communities in Canada, and thus the Ministry of Health and Long-Term Care (MOHLTC) also defines Northern communities separately from rural communities for planning purposes. ${ }^{4}$

Rural residents differ significantly from their urban counterparts on key health indicators and determinants of health. Life expectancy is generally lower in rural areas, from 65.4 years in northern Quebec to 81.2 years in Richmond, British Columbia. ${ }^{3}$ All-cause mortality rates are also higher in rural areas, pushed up by circulatory diseases, injuries (especially occupational injuries) and suicide. Conversely, all-cancer mortality rates are significantly lower in rural areas, as is the prevalence of obesity. ${ }^{5}$

Demographic problems, geographic isolation and the socioeconomic status of rural residents all intertwine to perpetuate rural-urban health inequities. Demographically, rural areas have more younger and older people, as opposed to urban areas, which have a higher ratio of people aged 30 to $59 .{ }^{3}$ Geographic isolation results in difficulty accessing and in bringing medical services to a community. Socioeconomic status is universally recognized as a key determinant of health and has been shown to significantly affect access to and ability to understand health information. Rural residents tend to have less higher education, more unemployment and lower incomes. For example, the average rural and urban unemployment rates in 2001 were $7.2 \%$ and $5.4 \%$ respectively. ${ }^{3}$ Coupled with the fact that access to safe drinking water is a major concern in some rural areas (a twin problem of geography and poverty), these facts leave little doubt as to the existence of rural-urban health inequity.

The increasing centralization of health services has meant that many rural hospitals have been downsized or closed, without a concurrent improvement in primary care services. This has had the dual effect of reducing access to health services in rural areas, as well as increasing unemployment. Furthermore, the centralization of health services has meant the centralization of physicians, who have become unequally distributed between rural and urban areas. For instance, $10.1 \%$ of physicians in Canada practice in rural areas. ${ }^{6}$
The reasons for the physician shortage are manifold. Some of them involve the nature of rural practices, which tend to require longer hours, more on-call time and ask doctors to provide more comprehensive services, due to a lack of access to investigations, labs and specialist consults. It has also been argued that the elimination of rotating internships in favour of a 2-stream approach, in which medical students choose either a 2-year family medicine residency or a 5-year specialist residency, has channeled many medical students away from family medicine and limited the exposures of family medicine residents. ${ }^{2}$ Furthermore, personal and lifestyle factors play a major role for physicians, in whether they choose to practice in rural areas. Arguably, medical schools choose socioeconomically advantaged students from urban areas, who are less likely to practice in rural areas than if they were from the areas themselves. ${ }^{2}$ This has been the major impetus behind Northern Ontario School of Medicine's (NOSM) setup and the recruitment of students from rural, remote and Northern communities into medical schools, through initiatives such as SWOMEN (Southwestern Ontario Medical Education Network).

Other authors point to a host of barriers, such as professional licensing that restricts other health care professionals from being able to provide the same services that doctors do, despite being able to do same work for cheaper. ${ }^{7}$ The authors also point out the fact that despite being called "collaborative" health care teams, the organization of many new models of primary care delivery still feature doctors as the managers of care. Nonetheless, it is important to recognize that there is a trade-off between expanding the scope of practice of allied health professionals to increase access to health care, and enacting professional licensing, which protects the public by ensuring the competency and adequate training of health professionals.

Rural areas are diverse and heterogeneous places. "Place"-in its physical, social, environmental and economic dimensions-matters. ${ }^{8}$ It may also explain why an Australian survey of rural residents found that geographical considerations did not rank as the most important factor in choosing to consult a doctor. In fact, the top mentioned factor was the respondents' comfort with their doctor. ${ }^{9}$ Certainly people must have physical access to health services, but their social access-in terms of how comfortable they feel in reaching out for help and understanding heath information-matters.

\section{THE CANADA HEALTH ACT AND THE ETHICS OF THE MATTER}

The primary objective of the Canada Health Act is to protect, promote and restore the physical and mental well-being of Canadian residents, by facilitating reasonable access to health services without financial or other barriers. ${ }^{14}$ Thus, where the Canada Health Act guarantees reasonable access to health care on uniform terms and conditions, with no direct or indirect barriers, it should be reason- 
able to presume that there should be equality of access to core health services whether a resident of a province lives in a rural or urban area. It is very difficult to make the delivery of health care services completely equal between rural and urban areas; to be frank, there isn't full equality of health care delivery between suburban and urban areas or even within urban areas. Many procedures and tests can only be done in tertiary care centres, which can only realistically exist in major urban centres, as they require key pieces of infrastructure and health personnel to function.

There is also a role for autonomy and personal choice in the rural-urban health divide. Residents of rural areas continue to live there while recognizing that they eschew certain benefits that might otherwise be available to city dwellers, including cultural, retail and education opportunities that lie outside of health care delivery. Is it really reasonable then to ask for full equality of access to all health care services? Furthermore from a utilitarian (and in turn a public health ethics) perspective, we should be funding whatever gives the most benefits for the largest number of people. As provinces tighten their belts in the age of austerity, this is a view that seems to resonate fiscally, especially since health care is seen as another "service" to be delivered. If other government services cannot be fully and equally delivered to rural and remote areas, then is it is reasonable to ask for full and equal delivery of health care, especially since the Canada Health Act specifically guarantees only "reasonable access" to health services?

Conversely, the Canada Health Act also lists various principles that provinces must abide by when delivering their health care. Arguably the law should ensure accessibility to core health services. From a rights-based ethical perspective, the rights of those living in rural areas to access health care are equal to the rights of those living in urban areas, and policies should be tailored around providing health services in that fashion. The philosopher John Rawls' concept of the veil of ignorance furnishes further grounds for a rights-based approach to planning health services delivery. The veil of ignorance asks us to structure society in our imaginations without knowing what sort of circumstances and what type of person we would be born as. As Rawls explained, most of us would see to it that society was organized in an egalitarian fashion that provided equal opportunity for all, whether they were born wealthy or impoverished, or perfectly healthy or disabled. Similarly, if we are born into or working in rural areas, in industries such as farming or natural resource extraction, we should have equal access to core health services that provide equal opportunity to "protect, promote and restore" our physical and mental well-being as much as Canadians living in urban areas do. Simply put, this is the promise of the Canada Health Act.

It is vitally important, however, to distinguish health inequity from disparities in health care delivery. The Canada Health Act guarantees reasonable access to health services, and yet as mentioned above, the social determinants of health, which tend to lie outside of health care delivery, play major roles in individual well-being. Health care delivery is only a piece of the puzzle: healthy public policy that addresses the root causes of poor health is just as important.

\section{RECOMMENDATIONS}

The list of proposed solutions for health care in rural areas is lengthy, and some have already materialized, as in the cases of the creation of the NOSM to recruit students from rural and Northern areas, or more general funding for rural health care. For instance, some current projects being funded in the Champlain Local Health Integration Network (LHIN) involve electronic medical record (EMR) funding, more regional pharmacies, support for a policy that takes care of patients at home as opposed to in hospital and support for patient-order sets based on evidenced-based practice guidelines. ${ }^{10}$ LHINs are regional health authorities in Ontario that are responsible for distributing health care funding and organizing health care services in their geographical area.

Many of the reports on the state of rural healthcare share common recommendations with a 2002 report titled "Rural Health in Rural Hands”, which was prepared by Health Canada's Ministerial Advisory Council. In the intervening years, provinces have undertaken ambitious efforts to restructure their health systems, from Ontario's decentralization of health planning to its LHINs, to Alberta's formation of a singular Health Services superboard.

In 2006 the Government of Ontario created HealthForceOntario in order to plan for the recruitment, retention and distribution of regulated health professionals in Ontario. The strategies that HealthForceOntario and other provinces use have been mentioned above. The ethical issues behind them are explored in another article in this issue (see "What should rural doctors expect? A basic ethical challenge for rural practice"). The Government of Ontario's own recommendations in 2011 suggested the further creation of a group responsible for rural, remote and northern health care within the MOHLTC. ${ }^{4}$

Conversely, the Rural Ontario Institute (ROI) has argued that the doctor shortage has not been solved by financial incentives only. They have argued for more organic approaches instead, such as recruiting medical students from rural areas, having more training in rural areas and having more satellite campuses in rural areas of urban medical schools. ${ }^{11}$ In a separate report the $\mathrm{ROI}^{12}$ also argued that provinces should expand the role of other health professionals, particularly nurse practitioners, in order to increase access to health care in rural areas. ${ }^{13}$

Whatever the proposals are, one can only hope that they work out. The Canada Health Act will turn 30 years old in a year from now and in my regards; its promise of free, public health care for all Canadians still has not been lived up to.

\section{REFERENCES}

1. Wooton J. New office to focus on rural health issues. Farm Family Health. 1999 Spring;7(1).

2. Laurent S. Rural Canada: access to health care [Internet]. Ottawa: Health Canada, Economics Division; 2002 [cited 2014 Jan 19]. Available from: http://publications.gc.ca/Collection-R/LoPBdP/ $\mathrm{BP} / \mathrm{prb0245-e.htm}$

3. Rural health in rural hands [Internet]. Ottawa: Ministerial Advisory Council on Rural Health (Canada); 2002 [cited 2014 Jan 19]. Available from: http://www.srpc.ca/PDF/rural_hands.pdf 


\section{LAW}

4. Rural and northern health care framework/plan [Internet].

Toronto: Ministry of Health \& Long Term Care (MOHLTC); 2011

[cited 2014 Jan 19]. Available from: http://www.health.gov.on.ca/

en/public/programs/ruralnorthern/docs/report rural northern EN.pdf

5. How healthy are rural Canadians [Internet]? Ottawa: Public Health Agency of Canada; 2006 Sep [cited 2014 Jan 19]. Available from: https://secure.cihi.ca/free_products/summary_rural_canadians_2006_e.pdf

6. Main page [Internet]. Shawville (QC): Society of Rural Physicians of Canada; 2014 [cited 2014 Jan 19]. Available from: http://www. srpc.ca

7. Bourgeault IL, Mulvale G. Collaborative health care teams in Canada and the US: confronting the structural embeddedness of medical dominance. Health Soc Rev. 2006;15:481-95.

8. Kulig JC, Williams AM. Health in rural Canada [Internet]. Vancouver: UBC Press; 2011 [cited 2011 Jan 19]. Available from: http://www.ubcpress.ca/books/pdf/chapters/2011/healthinruralcanada.pdf

9. Humphreys JS, Mathews-Cowey S, Weinand HC. Factors in accessibility of general practice in rural Australia. Med J Aust. 1997;166(11):577-580.

10. Improving patient care in small and rural hospitals [Internet]. Ottawa: Champlain Local Health Integration Network; 2013 May [cited 2014 Jan 19]. Available from: http://www.champlainlhin. on.ca/newsroom display.aspx?id=7590.

11. Pong R, Russell N. A review and synthesis of strategies and policy recommendations on the rural health workforce [Internet]. Sudbury (ON): Rural Ontario Institute, 2003 [cited 2014 Jan 10]. Available from: http://ruralontarioinstitute.ca/file.aspx?id=fdc2fb3f-7771-4791-89cd-86856524fd74.

12. The Ontario Rural Council. Rethinking rural health care: innovations making a difference. Guelph (ON): Rural Ontario Institute; 2009 [cited 2014 Jan 19]. Available from: http://ruralontarioinstitute.ca/file.aspx?id=1fb3035d-7c0e-4bfa-a8d7-783891f5c5dc.

13. Supply, distribution and migration of Canadian physicians, 2011. Ottawa: Canadian Institute for Health Information; 2011 [cited 2014 Jan 19]. Available from: https://secure.cihi.ca/estore/productFamily.htm?locale=en\&pf=PFC1968.

14. Canada Health Act of 1985, R.S.C., c. C-6. 